\title{
RESENHA DE MACHADO DE ASSIS EM PERSPECTIVA: FICÇÃO, HISTÓRIA E MANIFESTAÇÕES SOCIAIS, EDITADO POR JURACY ASSMANN SARAIVA E REGINA ZILBERMAN
}

REVIEW OF MACHADO DE ASSIS IN PERSPECTIVE:

FICTION, HISTORY, AND SOCIAL MANIFESTATIONS, EDITED BY JURACY ASSMANN SARAIVA AND REGINA ZILBERMAN

SARAIVA, Juracy Assmann; ZILBERMAN, Regina (Orgs). Machado de Assis em perspectiva: ficção, história e manifestações sociais. São Leopoldo: Oikos, 2019. 208 p.

\section{JAMES REMINGTON KRAUSE}

Brigham Young University

Provo, Utah, EUA

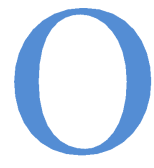

rganizado por duas machadianas renomadas, Juracy Assmann Saraiva e Regina Zilberman, Machado de Assis em perspectiva: ficção, história e manifestações sociais "é resultado de investigações dos membros dos grupos de pesquisa 'Ficção de Machado de Assis: sistema poético e contexto"' (SARAIVA; ZILBERMAN, 2019, p. 7). Como explicam as organizadoras na introdução, o livro "atende a um amplo escopo de leitores, que encontram em Machado de Assis motivação para aprofundar seu conhecimento sobre a literatura e sobre os imponderáveis da natureza humana" (SARAIVA; ZILBERMAN, 2019, p. 12). Com esse fim, reúne-se uma dúzia de artigos de temas abrangentes de críticos já estabelecidos e emergentes. Apesar de seu enfoque, todo leitor crítico de Machado irá achar algo de grande valor nesse conjunto de ensaios. 
No seu ensaio "O estranho narrador de Quincas Borba e o problema do realismo", Antônio Marcos Vieira Sanseverino problematiza a "instabilidade de posição do narrador". Por um lado, o narrador externo e heterodiegético tende a reforçar a "objetividade realista" oitocentista do cotidiano brasileiro, sob a ótica do período escravista (SANSEVERINO, 2019, p. 15). Por outro lado, ele "faz questão de interromper o fluxo narrativo para comentar, desqualificar [e] rebaixar" o protagonista Rubião (SANSEVERINO, 2019, p. 35). Através de uma análise nítida e meticulosa dos comentários sardônicos do narrador, Sanseverino (2019, p. 29; p. 36) demonstra que ele "é um cidadão culto, erudito, da elite letrada brasileira que olha para Rubião com desprezo", e por extensão para o leitor, "mostrando que ambos são incapazes de compreender os acontecimentos narrados".

Atílio Bergamini, em "Machado marmota: os primeiros anos do contista", oferece uma análise dos primeiros contos de Machado "como um todo". Ele focaliza em alguns topoi unificadores, como "a viagem, a negociação, a traição e o engano" nos seguintes contos: "Três tesouros perdidos", "O país das quimeras: conto fantástico", "Frei Simão", "Virginius: narrativa de um advogado", "O anjo das donzelas", "Casada e viúva", "Questão de vaidade" e "Confissões de uma viúva moça" (BERGAMINI, 2019, p. 50). Segundo Bergamini (2019, p. 53), ao longo dos anos, houve um deslocamento na perspectiva de Machado de um "encadeamento 'externo' de ações limitadas" a um "encadeamento 'interno', em que a consciência e personagens se torn[ou] o foco do interesse". Outrossim, "o objeto dos modos de ler se tornou o sujeito da análise, com vistas a uma crítica do sujeito dos modos de ler" (BERGAMINI, 2019, p. 53). Desde o início é possível traçar esse percurso que iria caracterizar a ficção do período maduro do autor.

Em "Costura entre moda e literatura, em Dom Casmurro", Cátia Silene Kupssinskü analisa a moda como mais um sistema simbólico de significação no romance machadiano. A moda parisiense na burguesia carioca oitocentista representava a modernização e civilização presentes do Brasil. Dentro desse sistema, os comentários de Bento Santiago sobre a moda servem predominantemente para assinalar diferenças de classe social, sobretudo dos personagens de José Dias e Capitu. Assim, Machado "oferece ao leitor a oportunidade de preencher lacunas propostas pelo jogo literário, questão que se dá por meio da apreensão dos significados sociais inerentes à moda" (KUPSSINSKÜ, 2019, p. 69). 
Em seu ensaio "A mulher negra e a mestiça em obras de Machado de Assis", Cláudia Santos Duarte e Marinês Andrea Kunz (2019, p. 75) analisam a presença de "mulheres negras escravizadas", e até certo ponto "as mulheres livres das camadas mais pobres" no romance Esaú e Jacó, no poema "Sabina", e nos contos "Mariana" e "O caso da vara". Segundo afirmam as autoras, Machado "[descreve] suas personagens com seus anseios, suas paixões, as violações, a objetificação, as condutas e a situação periférica que instauraram na mulher negra uma história de abusos, de superação e, principalmente, de resistência" (DUARTE; KUNZ, 2019, p. 80).

Pisando em território familiar, Débora Bender analisa as alusões a peças teatrais em "Cultura dramática em Dom Casmurro". Bender focaliza principalmente a intertextualidade entre Dom Casmurro e Fausto de Goethe e Otelo e Macbeth de Shakespeare, chamando o romance "um misto" dessas três peças, sobretudo na sua capacidade de "revelar e problematizar a essência humana" (BENDER, 2019, p. 93). No final das contas, a arte, para Machado, "tem a função de educar seus receptores e de denunciar mazelas sociais, daí ser um púlpito e uma tribuna" (BENDER, 2019, p. 93), o que sua inspiração em consagradas obras dramáticas providencia.

Em "'A causa secreta' sob a luz da semiótica: um estudo do limiar", Ernani Mügge analisa o conto desde um olhar narratológico, segundo conceitos semióticos de Dino del Pino. Mügge divide o conto em três segmentos. Segmento 1, o limiar de entrada, consiste nos primeiros dois parágrafos do conto, nos quais se apresentam os personagens com um tom inquietante. O Núcleo Diegético apresenta-se em analepse, narrando os eventos desde os primeiros encontros entre Garcia e Fortunato até o clímax e o começo do dénouement, isso é, o momento de abertura do conto. Segmento 2, o limiar de saída, é o desfecho propriamente dito - a doença e morte de Maria Luísa, o beijo de Garcia no seu cadáver e os soluços sadomasoquistas de Fortunato. Neste enquadramento, Mügge analisa os posicionamentos relacionais entre sujeito e objeto através de estímulos distais e proximais. Uma vez que o narrador se situa fora do espaçotempo diegético, o leitor também usufrui de uma focalização externa ao texto e assim presencia o universo artístico machadiano.

Juracy Assmann Saraiva estuda a importância de espaços festivos em "Reflexão estética e manifestações populares em Memórias póstumas de Brás Cubas". Por um lado, os "leitores ilustrados", com um conhecimento dos textos 
consagrados do cânone, podiam apreciar a intertextualidade que Machado tentava criar através das alusões (SARAIVA, 2019, p. 111). Por outro lado, os leitores contemporâneos de Machado também reconheciam as múltiplas referências a "aspectos da sociedade carioca" daquela época como "ritos de integração no espaço familiar, festas cívicas e religiosas, normas de ordenamento social, superstições ou crendices, a medicina popular [e] formas de lazer" (SARAIVA, 2019, p. 128; p. 112). Ao decifrarem as referências implícitas e explícitas aos dois âmbitos - o erudito e o cotidiano - os leitores, como assinala Saraiva (2019, p. 127), conseguem "compreender não só a metabiografia do autordefunto, mas também aquilatar posicionamentos do escritor diante do texto que produz".

Kenneth David Jackson (2019, p. 131), em "A miscelânea machadiana: os estranhos objetos e as criaturas das fábulas morais", analisa como Machado segue e desenvolve a tradição de fabulista ao personificar uma porção de "objetos esdrúxulos". Machado apresenta esses "agentes independentes e inusitados" como sinédoques ou metonímias, convertendo-os em fetiches que "afastam os tabus ao dizer de outra maneira o que não pode ser dito [e que] servem de referência irônica e satírica à melancólica humanidade" (JACKSON, 2019, p. 133). Os leitores que desenredam a "retórica de dissimulação e de substituição" conseguirão "perceb[er] e particip[ar] da estratégia sutil do jogo, armado por um autor que fala por inferências, subentendidos e alusões, inventando novos contextos para fábulas sobre o comportamento e a sabedoria humanos" (JACKSON, 2019, p. 140).

Marcelo Diego começa seu artigo, "A obra de arte total de Machado de Assis", delineando as influências principais no desenvolvimento do romance brasileiro: o romance europeu setecentista, o romance-folhetim, as narrativas de viagem, os tratados naturais e a ópera. Diego (2019, p. 148) alega que a ópera europeia "teve um impacto maior sobre a literatura brasileira do que sobre a ópera brasileira". Ele observa que "espacialmente, a cultura da ópera e a cultura do romance floresceram em um mesmo ambiente, junto a um mesmo público" (DIEGO, 2019, p. 149). O compositor alemão Richard Wagner desenvolveu seu conceito de ópera total que possibilitava a imersão total do espectador em todas as formas de arte (literatura, teatro, música, artes visuais). Do mesmo modo, Machado procurava uma totalidade mergulhadora no romance. Se Wagner "buscava o sentido de totalidade ao aproximar ao máximo o espectador da ação 
de suas óperas, Machado buscava esse mesmo sentido ao afastar o leitor da ação dos seus romances, chamando atenção para a natureza ficcional deles" (DIEGO, 2019, p. 149).

Em "'Capítulo dos chapéus': uma epopeia invertida", Paul Dixon analisa várias alusões a poemas épicos em alguns dos mais célebres textos machadianos. Depois de apresentar exemplos do tropo machadiano (Quincas Borba e a Odisseia; Dom Casmurro e Os Lusíadas), Dixon faz uma leitura comparada - mas, como o título indica, invertida - entre $A$ Ilíada, o épico clássico de Homero, e o conto "Capítulo dos chapéus". Ao trocar papéis e características dos personagens (Mariana por Aquiles e Conrado por Agamenão), Dixon oferece uma interpretação do "desfecho um pouco indefinido" que também é uma reviravolta. Em vez de ver Mariana como "uma pessoa débil, sem estômago para escaramuças na guerra dos sexos, [ela] é uma pessoa com uma consciência mais aguda das posições autênticas de uma pessoa justa e livre (DIXON, 2019, p. 159).

Em "'A Sereníssima República' - ética e política na última década da monarquia brasileira", Regina Zilberman (2019, p. 164) alega que na década de 1880 foi através do conto que Machado divulgava "suas preocupações estéticas e políticas". O conto, segundo uma nota do autor, aborda o tema de "nossas alternativas eleitorais [...] através da forma alegórica" (ZILBERMAN, 2019, p. 164). Zilberman (2019, p. 164) explica que Machado se referia à Lei Saraiva que "instituiu a eleição direta para todos os cargos do império e o uso do título de eleitor, documento que habilitava à participação no pleito". Para poder votar, ela explica, "cada cidadão deveria ser alfabetizado e comprovar" que possuía certo valor de renda líquida, "o que restringiu drasticamente o número de eleitores no país" (ZILBERMAN, 2019, p. 164-165). Se há uma moral na alegoria sobre a república das aranhas, segundo Zilberman (2019, p. 175), "não se trata de escolher entre monarquia e república, voto direto ou sorteio, mas de honestidade eleitoral, ausente nos pleitos". Para Machado, "não era a forma de governo que fazia a diferença, e sim a ação das pessoas que almejavam o poder e utilizavam os mecanismos legais disponíveis para obtê-lo" (ZILBERMAN, 2019, p. 175).

Em "Também se goza por influxo dos lábios que narram: Dom Casmurro e o ensino de Literatura", Tatiane Kaspari apresenta um roteiro de leitura do romance machadiano baseado nas teorias de recepção (Jauss e Iser) e performance (Zumthor). A abordagem pedagógica, alicerçando-se nos princípios de roteiros de leitura estabelecidos por Juracy Saraiva Assmann, apresenta três 
etapas metodológicas: "preparação para a recepção do texto; leitura compreensiva e interpretativa; transferência e aplicação de leitura" (KASPARI, 2019, p. 183). O roteiro de leitura é dividido em nove módulos com exercícios de pré-leitura, leitura e pós-leitura, acompanhados por "comentários ao professor". Kaspari fornece uma análise cuidadosa do texto que será de utilidade para leitores experientes e iniciantes de igual forma.

\section{Referências}

BENDER, Débora. Cultura dramática em Dom Casmurro. In: SARAIVA, Juracy Assmann; ZILBERMAN, Regina (Orgs). Machado de Assis em perspectiva: ficção, história e manifestações sociais. São Leopoldo: Oikos, 2019.

BERGAMINI, Atílio. Machado marmota: os primeiros anos do contista. In: SARAIVA, Juracy Assmann; ZILBERMAN, Regina (Orgs). Machado de Assis em perspectiva: ficção, história e manifestações sociais. São Leopoldo: Oikos, 2019.

DIEGO, Marcelo. A obra de arte total de Machado de Assis. In: SARAIVA, Juracy Assmann; ZILBERMAN, Regina (Orgs). Machado de Assis em perspectiva: ficção, história e manifestações sociais. São Leopoldo: Oikos, 2019.

DIXON, Paul. 'Capítulo dos chapéus': uma epopeia invertida. In: SARAIVA, Juracy Assmann; ZILBERMAN, Regina (Orgs). Machado de Assis em perspectiva: ficção, história e manifestações sociais. São Leopoldo: Oikos, 2019.

DUARTE, Cláudia Santos; KUNZ, Marinês Andrea. A mulher negra e a mestiça em obras de Machado de Assis. In: SARAIVA, Juracy Assmann; ZILBERMAN, Regina (Orgs). Machado de Assis em perspectiva: ficção, história e manifestações sociais. São Leopoldo: Oikos, 2019.

JACKSON, Kenneth David. A miscelânea machadiana: os estranhos objetos e as criaturas das fábulas morais. In: SARAIVA, Juracy Assmann; ZILBERMAN, Regina (Orgs). Machado de Assis em perspectiva: ficção, história e manifestações sociais. São Leopoldo: Oikos, 2019.

KASPARI, Tatiane. Também se goza por influxo dos lábios que narram: Dom Casmurro e o ensino de Literatura. In: SARAIVA, Juracy Assmann; ZILBERMAN, Regina (Orgs). Machado de Assis em perspectiva: ficção, história e manifestações sociais. São Leopoldo: Oikos, 2019. 
KUPSSINSKÜ, Cátia Silene. Costura entre moda e literatura, em Dom Casmurro. In: SARAIVA, Juracy Assmann; ZILBERMAN, Regina (Orgs). Machado de Assis em perspectiva: ficção, história e manifestações sociais. São Leopoldo: Oikos, 2019.

SANSEVERINO, Antônio Marcos Vieira. O estranho narrador de Quincas Borba e o problema do realismo. In: SARAIVA, Juracy Assmann; ZILBERMAN, Regina (Orgs). Machado de Assis em perspectiva: ficção, história e manifestações sociais. São Leopoldo: Oikos, 2019.

SARAIVA, Juracy Assmann. Reflexão estética e manifestações populares em Memórias póstumas de Brás Cubas. In: SARAIVA, Juracy Assmann; ZILBERMAN, Regina (Orgs). Machado de Assis em perspectiva: ficção, história e manifestações sociais. São Leopoldo: Oikos, 2019.

; ZILBERMAN, Regina (Orgs). Machado de Assis em perspectiva: ficção, história e manifestações sociais. São Leopoldo: Oikos, 2019.

ZILBERMAN, Regina. 'A Sereníssima República' - ética e política na última década da monarquia brasileira. In: SARAIVA, Juracy Assmann; ZILBERMAN, Regina (Orgs). Machado de Assis em perspectiva: ficção, história e manifestações sociais. São Leopoldo: Oikos, 2019.

JAMES REMINGTON KRAUSE é professor adjunto na Universidade Brigham Young e já publicou diversos artigos sobre a recepção de Machado de Assis e João Guimarães Rosa em tradução inglesa e também sobre o desenvolvimento do conto fantástico brasileiro. (iD) https://orcid.org/0000-0001-8129-5389. E-mail: jameskrause@byu.edu

Recebido: 05.11.2019

Aprovado: 07.11.2019 